\title{
Propagação de três espécies de carqueja com estacas de diferentes tamanhos
}

\section{Propagation of three species of Baccharis using different cutting leghts}

\author{
Claudine Maria de Bona ${ }^{1}$; Luiz Antonio Biasi²*; Flávio Zanette ${ }^{3}$; Tomoe Nakashima ${ }^{4}$
}

\section{Resumo}

O objetivo desse trabalho foi avaliar o tamanho da estaca caulinar na propagação vegetativa de três espécies de carqueja. A espécie Baccharis trimera foi coletada no município de Pinhais-PR, Baccharis articulata em Castro-PR e Baccharis stenocephala em Campina Grande do Sul-PR. Os experimentos de estaquia foram instalados no mês de maio, numa casa-de-vegetação com nebulização intermitente e com substrato de casca de arroz carbonizada. Os tamanhos das estacas utilizadas foram de 5, 10, 15 e $20 \mathrm{~cm}$ de comprimento. O delineamento experimental utilizado foi em blocos ao acaso com quatro repetições de 15 estacas por parcela, para cada experimento, um para cada espécie. Para $B$. trimera todas as variáveis apresentaram aumento com o maior tamanho da estaca. As estacas de $20 \mathrm{~cm}$ alcançaram os maiores níveis de brotação (93,3\%), enraizamento (100\%) e desenvolvimento do sistema radicial. A B. articulata apresentou o menor índice de enraizamento entre as três espécies testadas, atingindo máximo de 36,7\% com o uso de estacas de $15 \mathrm{~cm}$. A maior quantidade de massa seca de raízes foi obtida com estaca de 20 $\mathrm{cm}$, que apresentou média de 7,9 raízes por estaca. $\mathrm{Na}$ B. stenocephala, a porcentagem de enraizamento apresentou tendência linear de aumento com o uso de estacas maiores, atingindo mais de $50 \%$ de enraizamento com estacas de $20 \mathrm{~cm}$, as demais variáveis não diferiram significativamente. Conclui-se que para a propagação vegetativa de $B$. articulata, $B$. trimera e $B$. stenocephala deve-se utilizar estacas com pelo menos $20 \mathrm{~cm}$ de comprimento.

Palavras-chave: Baccharis trimera, Baccharis articulata, Baccharis stenocephala, estaquia.

\begin{abstract}
The objective of this work was to evaluate the effect of different cutting sizes on the vegetative propagation of three species of Baccharis. Baccharis trimera was collected in the municipal district of Pinhais-PR, Baccharis articulata in Castro-PR and in Mandirituba-PR and Baccharis stenocephala in Campina Grande do Sul-PR. In May 2000, the cuttings were placed in carbonized rice peels substrate and were rooted in a greenhouse, under intermittent mist. Cuttings of 5, 10,15 and $20 \mathrm{~cm}$ long were randomly distributed in four replications with fifteen cuttings in each parcel, for each one of the species. In $B$. trimera, the longer the cutting the better the rooting response and the $20 \mathrm{~cm}$ cuttings presented $93.3 \%$ of shooting, $100 \%$ of rooting and the best root system development. $B$. articulate presented the lowest rooting indices among the three species with a maximum of $35.7 \%$ of rooting in the $15 \mathrm{~cm}$ long cuttings and highest weight of dried rooting in the $20 \mathrm{~cm}$ long cuttings, which presented 7.9 roots per cutting. Rooting in B. stenocephala increased in linear tendency with cutting lenght and $20 \mathrm{~cm}$ long cuttings reached more than $50 \%$ of rooting. Other parameters had no differences among treatments. The $20 \mathrm{~cm}$
\end{abstract}

1 Engenheira Agrônoma, Mestre, Doutoranda na Texas A\&M University, USA.

2 Bolsista de Produtividade em Pesquisa do CNPq. Departamento de Fitotecnia e Fitossanitarismo. SCA. UFPR. Caixa Postal 19061, CEP 81531-990, Curitiba-PR.E-mail: biasi@ufpr.br.

3 Departamento de Fitotecnia e Fitossanitarismo. SCA. UFPR.

4 Departamento de Farmácia.SCS.UFPR.

* Autor para correspondência. 
long cuttings are recommended to be used in the propagation of $B$. articulata, B. trimera and $B$. stenocephala by cuttings.

Key words: Baccharis trimera, Baccharis articulata, Baccharis stenocephala, rooting.

\section{Introdução}

A carqueja é uma espécie pertencente à família Asteraceae, nativa da América do Sul, muito utilizada pelo seu efeito medicinal, sendo alvo de extrativismo devido à grande demanda pela indústria de fitoterápicos. É utilizada popularmente como digestiva, diurética, hapatoprotetora, hipoglicêmica e no combate da anemia (DE BONA et al., 2002).

O fato da carqueja ser uma espécie nativa de fácil estabelecimento a campo causou, até algum tempo atrás, a falsa impressão de não haver necessidade de cultivo, acarretando problemas na qualidade do produto final devido ao extrativismo desenfreado e irresponsável.

A maior parte das espécies vegetais nativas no Brasil é colhida por processos extrativos, sem que haja fiscalização eficiente por parte dos órgãos responsáveis, com isto o material colhido, do ponto de vista quantitativo, é muito heterogêneo e muitas vezes de baixa qualidade (DI STASI, 1996). O produto resultante do extrativismo geralmente possui mistura de espécies, pois no Brasil, a Subtribo Baccharidinae Hoffman é representada por quatro gêneros e tem aproximadamente 125 espécies (BARROSO, 1976).

A ausência de cultivo da carqueja, a sua eliminação das áreas agrícolas e o extrativismo têm reduzido as áreas de coleta, levando a obtenção da carqueja em áreas de pastagens, campos e beiras de estradas, onde a qualidade é prejudicada pela mistura de espécies, contaminação química por produtos utilizados na pastagem e nos animais ou por gases expelidos por veículos e contaminação microbiológica ocasionada pela presença de animais (DE BONA et al., 2002). Outras falhas no processo produtivo foram levantadas por Carvalho et al. (2003), a coleta independentemente da época do ano, secagem em temperaturas elevadas, avaliação apenas visual para caracterizar a espécie e grande variabilidade na composição do óleo essencial foram detectadas. Estas drogas são repassadas para empresas de beneficiamento e manipulação, que nem sempre executam controle de qualidade sobre os produtos adquiridos (BACCHI, 1996).

Reis e Mariot (1998) afirmaram que a exploração de plantas de uso medicinal da flora nativa através da extração direta nos ecossistemas (extrativismo), tem levado a reduções drásticas das populações naturais destas espécies, seja pelo processo predatório de exploração, seja pelo desconhecimento dos mecanismos de perpetuação das mesmas.

A carqueja está entre as dez espécies mais consumidas no estado de São Paulo. Reis e Mariot (2001) alertaram para o fato de que a carqueja (Baccharis spp.) é uma das espécies nativas mais exploradas na região do Vale do Ribeira do Iguape (Sudoeste de SP) levando a redução drástica das populações naturais.

Nesse sentido, para iniciar o cultivo da carqueja é necessário definir a forma de produção de mudas, sendo a estaquia um processo rápido e de baixo custo, que permite a manutenção das características de interesse agronômico e farmacológico nas mudas produzidas, evitando a mistura de espécies e genótipos não interessantes, por se tratar de uma forma de propagação assexuada.

Este experimento teve como objetivo avaliar o tamanho da estaca caulinar na propagação vegetativa de três espécies de carqueja.

\section{Material e métodos}

Para a realização dos experimentos, o material vegetal foi coletado sempre no período da manhã em três localidades diferentes: a espécie Baccharis trimera foi coletada no matrizeiro do Setor de Plantas 
Medicinais da Fazenda Experimental do Canguiri, da Universidade Federal do Paraná, Pinhais-PR, a espécie Baccharis articulata, na estrada do Cerne, a $20 \mathrm{Km}$ de Castrolanda, Castro-PR e a espécie Baccharis stenocephala, próximo à represa Capivari-Cachoeira, na localidade de Terra Boa, em Campina Grande do Sul-PR. Como as populações de $B$. articulata e $B$. stenocephala eram pequenas, com cerca de cinqüenta a sessenta plantas, as amostras coletadas para a instalação dos experimentos continham material de quase todas as plantas.

A identificação botânica foi feita pelo Professor Olavo de Araújo Guimarães e as exsicatas foram incorporadas ao Herbário do Setor de Ciências Biológicas da Universidade Federal do Paraná, catalogadas sob os seguintes números: 43370 para B. articulata, 40708 para B. stenocephala e 45093 para $B$. trimera.

Os experimentos de estaquia foram conduzidos em bancadas de madeira de 4,0 $\mathrm{m}$ de comprimento por 1,0 m de largura, elevadas 1,2 $\mathrm{m}$ do chão e preenchidas com casca de arroz carbonizada, na casade-vegetação do Departamento de Fitotecnia e Fitossanitarismo da UFPR, em Curitiba-PR. Os experimentos foram mantidos sob condição de nebulização intermitente, com rega de 2 minutos a cada 30 minutos de intervalo.

A instalação do experimento com $B$. trimera ocorreu no dia 25/05/00, B. articulata no dia 26/05/ 00 , e B. stenocephala no dia $30 / 05 / 01$, e as avaliações foram realizadas no dia $01 / 08 / 00$ para as duas primeiras e 31/07/01 para a última.

Os tratamentos foram compostos por cinco tamanhos de estacas: 5, 10, 15 e $20 \mathrm{~cm} \mathrm{de}$ comprimento. O delineamento utilizado foi em blocos ao acaso com quatro repetições de 15 estacas por parcela para os três experimentos. Os resultados obtidos nos experimentos foram submetidos ao teste de Bartlet e depois à análise de variância. Onde o Teste $\mathrm{f}$ foi significativo, as médias foram analisadas pelo teste de Tukey para as variáveis qualitativas e regressão polinomial para as variáveis quantitativas.

Os dados coletados foram os seguintes: porcentagem de estacas enraizadas calculada pelo número de estacas que emitiam pelo menos uma raiz visível em relação ao total de estacas da parcela; porcentagem de estacas com brotação calculada pelo número de estacas com pelo menos uma brotação maior que $1 \mathrm{~cm}$ em relação ao total de estacas da parcela; massa seca de raízes calculada pela pesagem das raízes emitidas pelas estacas após 48 horas em estufa a $70^{\circ} \mathrm{C}$; e número de raízes por estaca calculado pela contagem do número de raízes primárias emitidas diretamente das estacas enraizadas sem as suas ramificações.

\section{Resultados e discussão}

Todas as variáveis analisadas para $B$. trimera apresentaram tendência de aumento com o aumento do tamanho da estaca, sendo esta tendência linear para a porcentagem de enraizamento e brotação (Figuras 1 e 2) e quadrática para a massa seca e o número de raízes emitidas por estaca (Figuras 3 e 4).

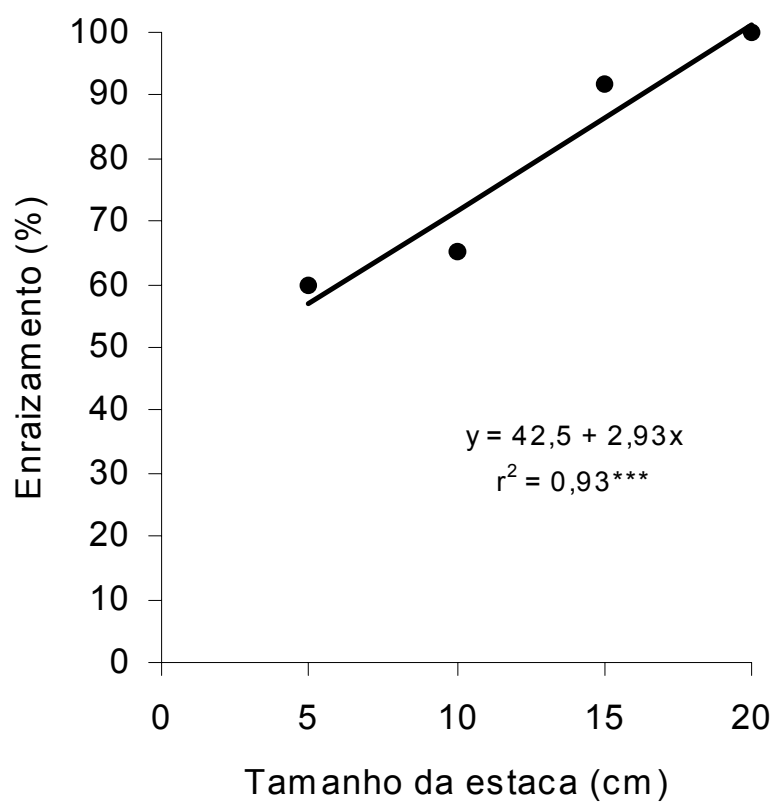

Figura 1. Influência do tamanho da estaca na porcentagem de enraizamento da $B$. trimera. 


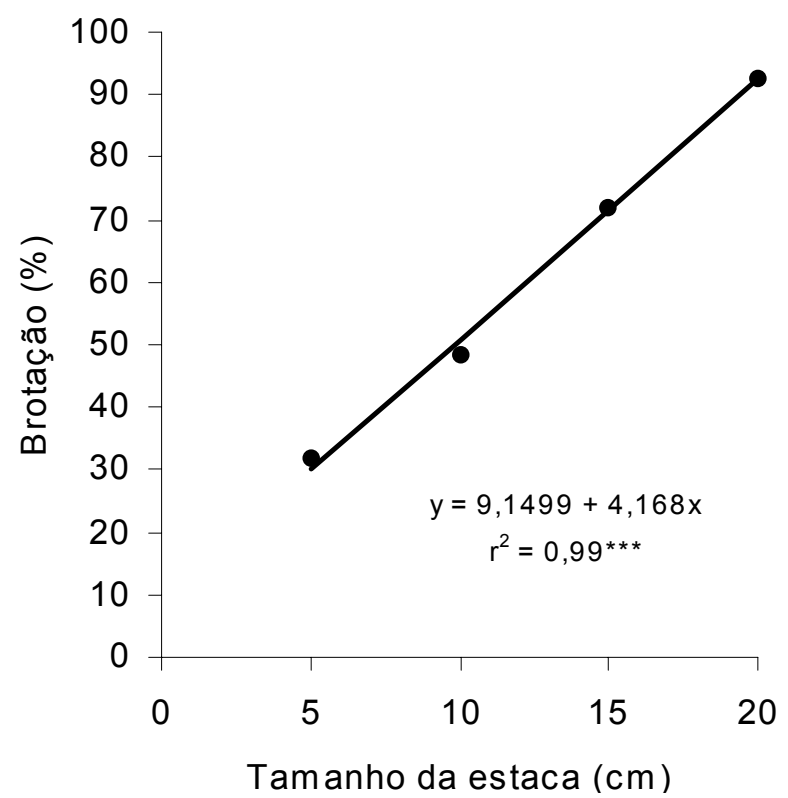

Figura 2. Influência do tamanho da estaca na porcentagem de brotação da $B$. trimera.

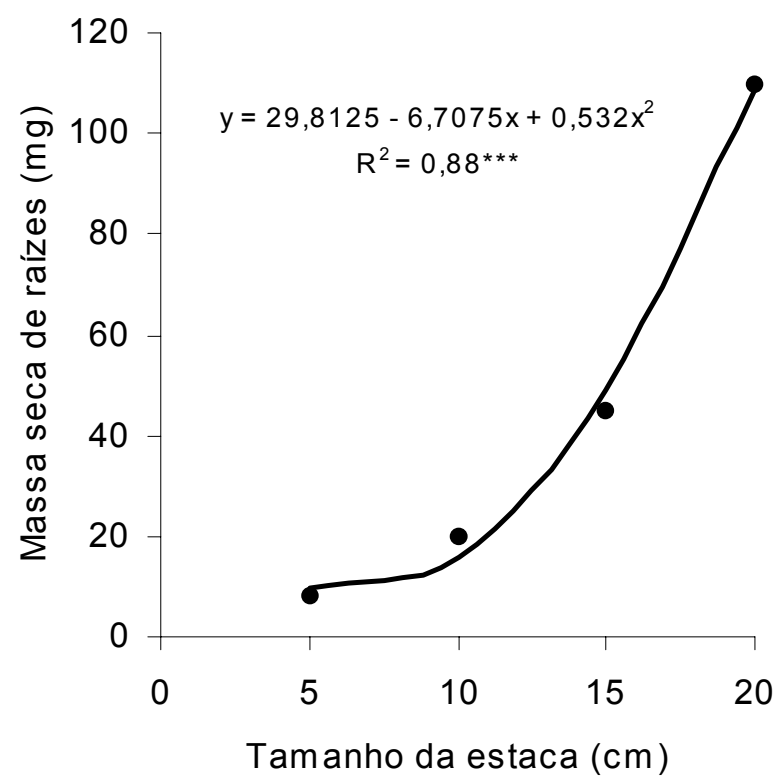

Figura 3. Influência do tamanho da estaca na quantidade de massa seca de raízes da $B$. trimera.

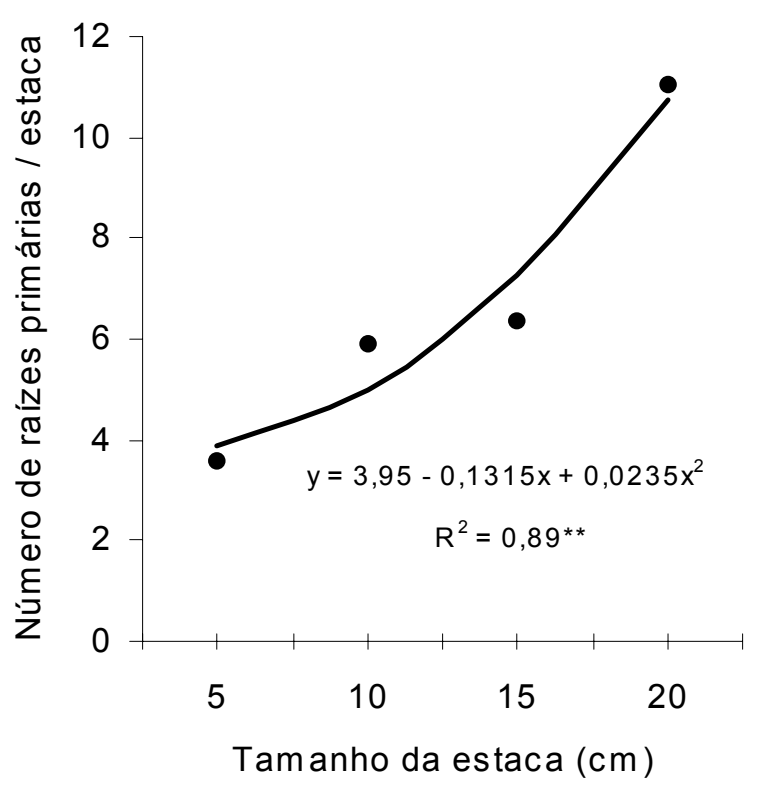

Figura 4. Influência do tamanho da estaca sobre o número de raízes por estaca da $B$. trimera.

As estacas de $20 \mathrm{~cm}$ alcançaram os maiores níveis de brotação $(93,3 \%)$, enraizamento (100\%) e desenvolvimento do sistema radicial, e os piores resultados foram obtidos com as estacas de $5 \mathrm{~cm}$. Biasi e De Bona (2000) observaram regressões lineares significativas entre o tamanho das estacas e o comprimento médio de brotações e o número de raízes emitidas por estaca em $B$. trimera.

A $B$. articulata apresentou o menor índice de enraizamento entre as três espécies testadas, atingindo em média 30,0\%, sem ocorrer diferença significativa entre os tratamentos. A maior quantidade de massa seca de raízes foi obtida com a estaca de $20 \mathrm{~cm}$, que foi superior às de $10 \mathrm{~cm}$ e $5 \mathrm{~cm}$ e não diferiu da estaca de $15 \mathrm{~cm}$, pelo teste de Tukey a 5\%. A estaca de $20 \mathrm{~cm}$ apresentou uma média de 7,9 raízes por estaca. Esses valores foram inferiores aos obtidos com $B$. trimera, que apresentou média de 10,7 raízes por estaca e quantidade de matéria seca de raízes 10 vezes maior para as estacas de $20 \mathrm{~cm}$. 
A porcentagem de enraizamento de $B$. stenocephala apresentou tendência linear aumentado com o maior tamanho das estacas, atingindo mais de $50 \%$ de enraizamento com estacas de $20 \mathrm{~cm}$ (Figura 5), enquanto as demais variáveis não diferiram significativamente. Apesar do bom enraizamento, o desenvolvimento das raízes foi pequeno no período avaliado, máximo de 2,9 raízes por estaca e massa seca inferior a $1 \mathrm{mg}$ nas estacas de $20 \mathrm{~cm}$.

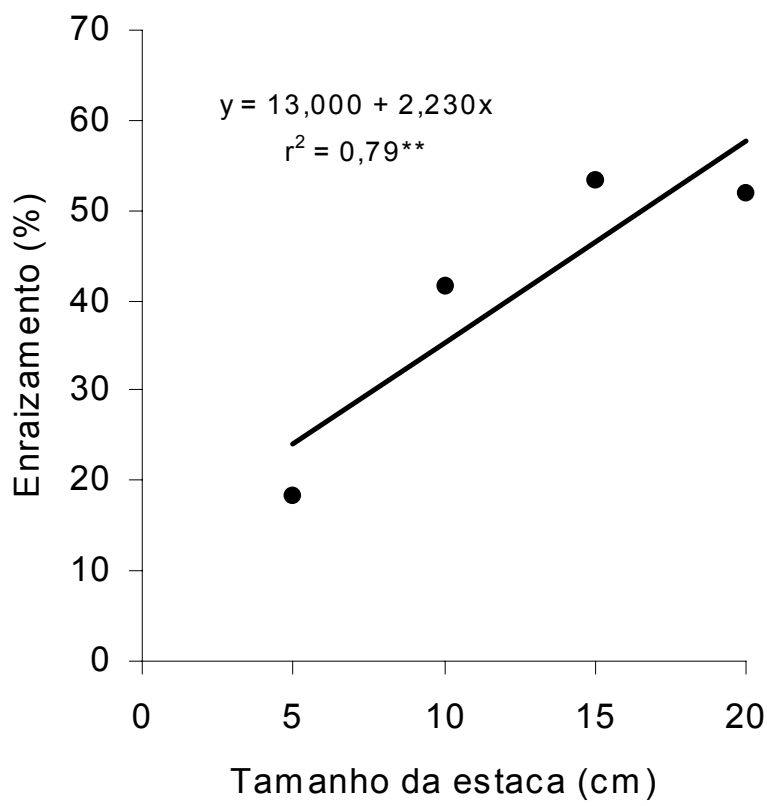

Fïgura 5. Intluência do tamanho da estaca na porcentagem de enraizamento da $B$. stenocephala.

A carqueja não apresenta folhas, mas o seu cladódio realiza a função de fotossíntese, sendo que estacas maiores possuem maior área fotossintética. Provavelmente, este fato e a maior quantidade de reservas, favoreceu o enraizamento das estacas de maior tamanho para as espécies testadas, porque, segundo Hartmann et al. (1997), estes são importantes fatores para o enraizamento.

Em espécies diferentes, testando-se também tamanho de estacas, Lopes, São José e Morais (1993) constataram aumento no volume de raízes em estacas de limeira ácida 'Tahiti' (Citrus latifolia Tan.) com 20 e $30 \mathrm{~cm}$ em relação às com $10 \mathrm{~cm}$ de comprimento. Lima, Almeida e Almeida (1992), no entanto, não observaram influência do tamanho da estaca sobre o enraizamento de estacas de acerola.

Os resultados obtidos para a estaquia no mês de maio indicaram que as espécies de carqueja testadas apresentam habilidade diferenciada na formação de raízes adventícias, a $B$. trimera é uma espécie de fácil enraizamento, a $B$. stenocephala possui maior dificuldade para enraizar e o crescimento das raízes adventícias é mais lento, e a $B$. articulata é uma espécie de difícil enraizamento.

\section{Conclusões}

A maior eficiência da propagação vegetativa de $B$. articulata, $B$. trimera e $B$. stenocephala foi obtida com estacas de $20 \mathrm{~cm}$ de comprimento.

A $B$. trimera apresentou maior enraizamento que a $B$. articulata e $B$. stenocephala.

\section{Agradecimentos}

Os autores agradecem ao Prof. Dr. Olavo de Araújo Guimarães do Departamento de Botânica do Setor de Ciências Biológicas da UFPR pelo valioso trabalho de identificação botânica das espécies estudadas.

\section{Referências}

BACCHI, E. M. Controle de qualidade de fitoterápicos. In: DI STASI, L. C. (Org.). Plantas medicinais: arte e ciência: um guia de estudo interdisciplinar. São Paulo: UNESP, 1996. p.169-186.

BARROSO, G. M. Compositae: subtribo Baccharidinae Hoffmann: estudo das espécies no Brasil. Rodriguésia, São Paulo, n.40, p.1-281, 1976.

BIASI, L. A.; DE BONA, C. M. Propagação de carqueja (Baccharis trimera (Less.) A.P. de Candolle) por meio de estaquia. Revista Brasileira de Plantas Medicinais, Botucatu, v.2, n.2, p.37-43, 2000.

DE BONA, C. M.; BIASI, L. A.; NAKASHIMA, T.; ZANETTE, F.; CORRÊA JÚNIOR, C. Carqueja: cultive esta idéia. Curitiba: SEAB/UFPR, 2002. 18p. 
DI STASI, L. C. Plantas medicinais: arte e ciência: um guia de estudo interdisciplinar. São Paulo: UNESP, 1996. 230p.

CARVALHO, R. I. N.; CARDON, L. M.; JAREMTCHUK, C. C.; KANAWATE, E. N.; SILVA, J. E. C. Carqueja e Espinheira Santa na Região Metropolitana de Curitiba: da produção ao comércio. Curitiba: Life Serviços Gráficos, 2003.44p.

HARTMANN, H. T. H.; KESTER, D. E.; DAVIES JR., F. T.; GENEVE, R. L. Plant propagation: principles and practices. 6.ed. New Jersey: Prentice Hall International, 1997. 770p.

LIMA, A. C. S.; ALMEIDA, F. A. C.; ALMEIDA, F. C. G. Estudos sobre o enraizamento de estacas de acerola (Malpighia glabra L.) Revista Brasileira de Fruticultura, Cruz das Almas, v.14, n.1, p.7-13, 1992.
LOPES, P. M. F.; SÃO JOSÉ, A. R.; MORAIS, O. M. Efeito do comprimento das estacas no enraizamento de limeira ácida "Tahiti”" (Citrus latifólia TAN.). Revista Brasileira de Fruticultura, Cruz das Almas, v.15, n.1, p.225-227, 1993.

REIS, M. S.; MARIOT, A. Manejo de populações naturais de plantas medicinais em Santa Catarina. In: JORNADA CATARINENSE DE PLANTAS MEDICINAIS, 1., 1998, Tubarão. Anais... Tubarão: UNISUL, 1998. p.83-90.

REIS, M. S.; MARIOT, A. Diversidade natural e aspectos agronômicos de plantas medicinais. In: SIMÕES, C. M. O.; SCHENKEL, E. P.; GOSMANN, G.; MELLO, J. C. P.; MENTZ, L. A.; PETROVICK, P. R. (Org.). Farmacognosia: da planta ao medicamento. 3. ed. Porto Alegre: UFSC, 2001. p.41-62. 